\title{
IDENTIFIKASI KEBERADAAN DAN JENIS MIKROPLASTIK PADA KERANG DARAH (Anadara granosa) DI PERAIRAN TANJUNG TIRAM, TELUK AMBON
}

\section{(Identification of Existance and Type of Microplastics in Cockle at Tanjung Tiram Waters, Ambon Bay)}

\author{
Novianty C. Tuhumury ${ }^{1 *}$ dan Agustina Ritonga ${ }^{2}$ \\ 1) Jurusan Manajemen Sumberdaya Perairan Fakultas Perikanan dan Ilmu Kelautan Universitas Pattimura \\ ${ }^{2}$ Mahasiswa Program Studi Manajemen Sumberdaya Perairan Fakultas Perikanan dan Ilmu Kelautan \\ Universitas Pattimura \\ *y_louhen@yahoo.com, agustinarolindaritonga@gmail.com \\ Corresponding author*
}

\begin{abstract}
ABSTRAK: Keberadaan sampah anorganik berupa plastik sangat membahayakan bagi kehidupan perairan. Plastik dapat terpecah menjadi ukuran mikro yang dikenal dengan mikroplastik. Keberadaan mikroplastik sangat berbahaya bagi biota perairan karena dapat dikonsumsi dan masuk ke saluran pencernaan. Tujuan dari penelitian ini yaitu mengidentifikasi keberadaan dan jenis mikroplastik pada kerang darah (Anadara granosa) di Tanjung Tiram perairan Teluk Ambon. Metode penelitian menggunakan observasi lapangan kemudian analisa laboratorium. Hasil penelitian menunjukkan bahwa pada kerang darah, telah ditemukan mikroplastik dengan jenis fiber sebanyak 360 pratikel dan fragmen sebanyak 61 pratikel. Keberadaan mikroplastik yang telah dikonsumsi oleh kerang darah akan berbahaya bukan hanya bagi biota perairan namun juga bagi manusia yang mengkonsumsi kerang darah tersebut. Plastik yang mengandung bahan kimia berbahaya akan terserap masuk ke dalam tubuh kerang darah. Berdasarkan hasil penelitian dapat disimpulkan bahwa mikroplastik telah berada dan dikonsumsi oleh kerang darah.
\end{abstract}

Kata Kunci: mikroplastik, kerang darah, fiber, fragmen, Tanjung Tiram

ABSTRACT: The existence of inorganic waste in the form of plastic is perilous for marine life. Plastics can be broken into micro size known as microplastics. Microplastic is harmful to marine biota because it can be consumed and entered the digestive tract. The purpose of this study was to identify the presence and types of microplastics in cockles blood clams (Anadara granosa) in Tanjung Tiram, Ambon Bay waters. The research method used field observations and laboratory analysis. The results showed that in cockles, fiber was found as much as 360 particles and 61 particles of fragments. The presence of microplastics that have been consumed by cockle will be harmful marine biota as well as humans who consume the cockles. Plastics that contain harmful chemicals will be absorbed into the body of cockles. Based on the results of the study, it can be concluded that microplastics have been found and consumed by cockles.

Keywords: microplastic, cockle, fiber, fragmen, Tanjung Tiram 


\section{PENDAHULUAN}

Dewasa ini, berbagai aktivitas yang dilakukan oleh manusia memberikan kontribusi yang positif maupun negatif baik bagi manusia maupun lingkungan. Sejalan dengan tingginya pertambahan penduduk yang mengakibatkan tingginya pula pemenuhan kebutuhan hidup manusia, maka dampak yang ditimbulkan lebih cenderung bernilai negatif khususnya bagi lingkungan (Steibl\&Laforsch, 2019. Salah satu permasalahan yang dialami oleh semua negara di dunia saat ini yaitu sampah. Sampah merupakan hsail buangan dari barang ataupun bahan yang tidak digunakan lagi seperti sisa makanan serta kemasan plastik makanan dan minuman. Tingginya produksi sampah yang dihasilkan sejalan dengan populasi penduduk mengingat setiap individu pastinya menghasilkan sampah dalam setiap aktivitas yang dilakukan.

Sampah plastik merupakan jenis sampah yang sulit terurai, membutuhkan waktu yang sangat lama untuk terurai. Penelitian membuktikan bahwa produksi plastik secara global mengalami peningkatan, di tahun 2017 mencapai 348 juta ton dan di tahun 2018 mencapau 359 juta ton (Plastics, 2019). Sifat plastik yang ringan, kuat dan tahan lama serta murah menyebabkan penggunaan plastik terus meningkat untuk kebutuhan sehari-hari. Sampah plastik yang dibuang ke wilayah pantai akan terbawa arus pasang surut dan akan mengendap pada ekosistem pesisir penting seperti mangrove, lamun dan terumbu karang. Keberadaan sampah plastik di wilayah pantai akan menurunkan nilai estetika pantai. Letak rumah penduduk yang sangat dekat dan membelakangi pantai merupakan penyebab tingginya kehadiran sampah plastik di pantai.

Seiring dengan berjalannya waktu, plastik yang terdapat di perairan akan mengalami proses degradasi. Proses ini disebabkan oleh beberapa faktor antara lain biodegradasi oleh mikroorganisme, serta fotodegradasi dengan memanfaatkan cahaya (Andrady, 2011). Plastik terdegradasi menjadi partikel yang lebih kecil yang dikenal sebagai mikroplastik, sehingga dapat terakumulasi di air laut dan sedimen (Hidalgo, et al., 2012). Mikroplastik merupakan partikel plastik yang berukuran kecil dan memiliki ukuran kurang dari $5 \mathrm{~mm}$ (Browne et $a l,, 2008)$. Terdapat dua tipe mikroplastik yaitu mikroplastik primer dan sekunder. Mikroplastik primer adalah hasil produksi plastik yang dibuat dalam bentuk mikro, seperti microbeads pada produk perawatan kulit yang masuk ke dalam saluran air. Mikroplastik sekunder merupakan pecahan, bagian, atau hasil fragmentasi dari plastik yang lebih besar (Zhang et al. 2017). Permasalahan yang timbul saat ini yaitu keberadaan mikroplastik di perairan dapat dikonsumsi secara langsung oleh biota perairan seperti ikan dan kerang. Hasil penelitian membuktikan bahwa mikroplastik dapat dikonsumsi karena menyerupai makanan (Browne et. al., 2008) dan dicerna oleh biota laut (Boerger et al. 2010). Keberadaan mikroplastik pada jaringan tubuh biota perairan dapat menganggu sistem pencernaan (Teuten $e t$ al., 2009; Rochman et al. 2015). Dampak lain yang ditimbulkan yaitu, mengurangi tingkat pertumbuhan, menghambat produksi enzim, menurunkan kadar hormon steroid, mempengaruhi reproduksi, dan dapat menyebabkan paparan aditif plastik lebih besar sifat toksik (Wright et al., 2013). Kandungan kimia plastik juga akan ikut terserap dalam tubuh biota perairan, sehingga jika dikonsumsi oleh manusia akan terjadi transfer toksik.

Penelitian tentang mikroplastik di perairan Teluk Ambon diperoleh informasi bahwa keberadaan mikroplastik ditemukan tinggi pada perairan Teluk Ambon Dalam khususnya di daerah Poka (Manullang, 2019). Hal ini bukan hanya dipengaruhi oleh tingginya aktivitas dan jumlah penduduk yang bermukim di sekitar daerah tersebut, namun juga dipengaruhi oleh pola sirkulasi arus di perairan Teluk Ambon Dalam. Pola sirkulasi arus memiliki waktu pembilasan yang lebih lama sehingga massa air dan juga keberadaan mikroplastik akan tinggal lebih lama di perairan tersebut.

Pemilihan kerang darah dalam penelitian ini karena biota tersebut dikonsumsi oleh masyarakat sekitar. Proses pengambilan kerang darah dilakukan pada saat air surut atau dikenal dengan "bameti". Sifat kerang darah seperti kerang pada umumnya yaitu filter feeder artinya bahwa kerang darah akan menyaring semua makanan di dalam tubuhnya seperti sedimen 
dan air laut. Beertolak dari sifat tersebut maka kontaminasi mikroplastik pada kerang darah sangat mungkin terjadi. Keberadaan mikroplastik pada sedimen dan air akan turut masuk ke dalam tubuh kerang darah, selain itu sistem pergerakannya yang lambat membuat kerang darah mudah terkena polusi lingkungan (Darmono, 2001). Berdasarkan uraian tersebut di atas maka penelitian tentenga keberadaan mikroplastik di perairan khususnya bagi biota perairan yang dikonsumsi oleh manusia sangat penting untuk dilakukan. Penelitian ini bertujuan untuk mengidentifikasi keberadaan dan jenis mikroplastik pada kerang darah (Anadara granosa) di Tanjung Tiram perairan Teluk Ambon

\section{METODE PENELITIAN}

Penelitian dilakukan pada bulan MaretApril 2019. Pengambilan sampel kerang darah dilakukan pada Tanjung Tiram, Perairan Teluk
Jurnal TRITON Volume 16, Nomor 1, April 2020, hal. 1 - 7 P-ISSN 1693-6493 E-ISSN 2656-2758 DOI: https://doi.org/10.30598/TRITONvol16issue1page1-7

Ambon Bagian Dalam. Metode yang digunakan dalam penelitian ini adalah observasi lapangan. Sampel yang telah diperoleh kemudian akan dianalisa lebih lanjut di Laboratorium Zoologi Fakultas MIPA Universitas Pattimura. Sampel kerang darah yang dianalisa berjumlah tiga buah dengan panjang berkisar antara 3,6-3,9 cm, lebar 3,2$3,6 \mathrm{~cm}$, dan tinggi 3,2-3,7 cm. Sampel kerang darah kemudian dibedah dan diambil bagian lambung dengan berat saluran pencernaan berkisar antara 2-3 gr. Selanjutnya dilarutkan dengan menggunakan larutan $\mathrm{KOH} \quad 10 \%$ selama 14 hari pengamatan (Tabel 1), dengan tujuan agar melarutkan semua bahan organik yang terkandung dalam saluran pencernaan dan menyisakan kandungan anorganik. Keberadaan dan jenis mikroplastik akan diamati dengan menggunakan mikroskop. Data yang diperoleh kemudian dianalisa secara deskriptif dengan menampilkan gambar dan dibahas lebih lanjut.

Tabel 1. Gambaran larutan sampel pada hari pengamatan

\begin{tabular}{ccc}
\hline Hari Pengamatan & Gambaran larutan sampel \\
\hline 1 & & \\
\hline
\end{tabular}


Tabel 2. Jenis mikroplastik yang ditemukan pada kerang darah

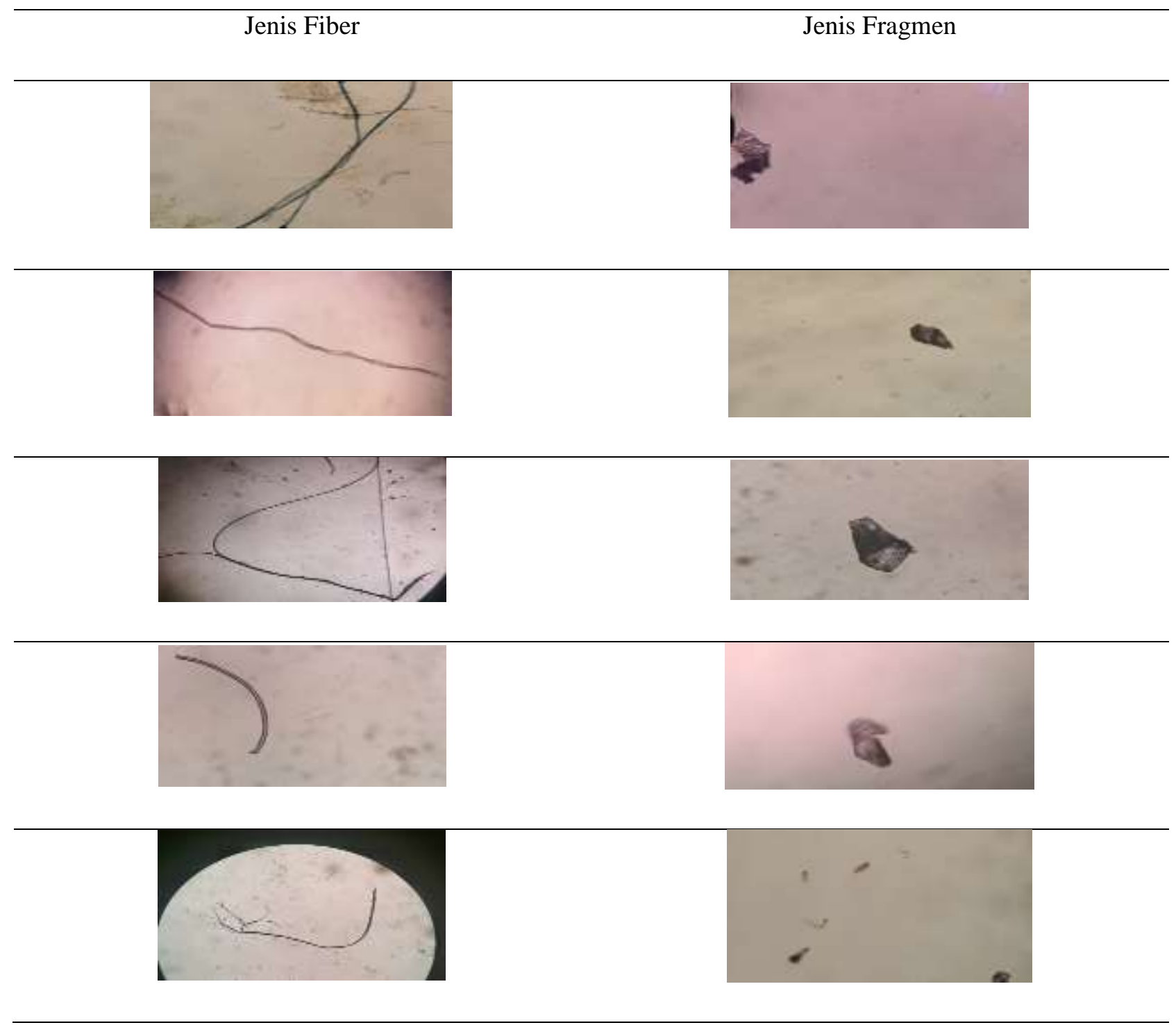

\section{HASIL DAN PEMBAHASAN}

Berdasarkan bentuk, mikroplastik diklasifikasikan sebagai fragmen (partikel tidak beraturan, kristal, bulu, bubuk, serpihan); serta (filamen, microfiber, helaian); manikmanik (biji, bulatan manik ukuran mikro); busa (polistiren); dan butiran (butiran resinat, nurdles, nib) (Lusher, et al., 2017). Mikroplastik yang didapat pada kerang darah di Tanjung Tiram adalah jenis fiber berbentuk seperti tali, dan fragmen berbentuk seperti lembaran kecil plastik (Tabel 2). Jumlah mikroplastik bentuk fiber ditemukan sebanyak 360 partikel, sedangkan bentuk fragmen sebanyak 61 partikel.
Mikroplastik yang paling banyak ditemukan pada kerang darah adalah jenis fiber. Mikroplastik jenis fiber bersumber dari tali perahu yang bersandar pada daerah pasang surut yang mengalami gesekan kemudian terurai menjadi partikel plastik dengan ukuran yang sangat kecil di dalam perairan. Sesuai dengan yang dikemukakan Browne, et al. (2011), mikroplastik jenis fiber berasal dari kain sintetis yang dapat terlepas akibat pencucian pakaian, jala ikan, bahan baku industri, alat rumah tangga, kantong plastik yang dirancang untuk terdegradasi di lingkungan, atau akibat pelapukan produk plastik. Hal ini sesuai dengan lokasi pengambilan sampel yang sangat dekat dengan pemukiman warga. Seperti diketahui, 
pemukiman penduduk yang berada di pesisir berpotensi besar untuk menghasilkan sampah plastik khususnya kantung plastik dan kemasan makanan atau minuman berupa plastik (Tuhumury\&Kaliky, 2019; Garcia, et al., 2019). Terdapat pula aktivitas nelayan yang melabuhkan perahunya di pantai pada daerah pasang surut. Beberapa bangkai kapal yang telah rusak dan alat tangkap berupa jaring juga terdapat di pesisir dan diduga memberikan kontribusi pada keberadaan mikroplastik di perairan (Ayuningtyas, dkk., 2019). Hal ini disebabkan oleh keberadaan bangkai kapal beserta perabotan didalamnya yang berbahan dasar plastik serta jaring akan mengalami proses degradasi.

Kerang darah termasuk dalam golongan biota laut yang pergerakannya lambat, hidupnya menetap dalam suatu habitat tertentu yaitu di sedimen atau di dasar laut sehingga bioakumulasi dan biokonsentrasi berlangsung secara lebih intensif. Akibatnya berbagai jenis cemaran yang ada di lingkungan perairan dapat masuk ke dalam tubuh kerang, termasuk mikroplastik. Mikroplastik mempunyai dampak kimiawi, fisik dan biologis terhadap organisme yang menelannya secara langsung maupun tidak langsung. Organisme yang menelannya secara tidak langsung melalui konsumsi mangsa yang terkontaminasi (Griet et al., 2015).

Berdasarkan hasil penelitian Fitri (2017) di tambak lorok Semarang pada waktu pengambilan 1 rata- rata jumlah particle suspected as microplastic (PSM) yang teridentifikasi pada kerang darah sebesar $5,1+3.5$ partikel/sampel dengan range 0-12 partikel/ sampel, pada waktu pengambilan 2 sebesar 5,3+ 3,13 partikel/ sampel dengan range 0-11. Sesuai dengan Li et al. (2015) yang menyebutkan ditemukannya mikroplastik pada kerang dengan rata-rata jumlah mencapai 4,6 partikel plastik/sampel pada kerang yang diambil dari laut bebas China. Dengan ditemukannnya mikroplastik pada kerang darah yang diambil di Pantai utara Pulau Jawa ini membuktikan bahwa kerang darah dapat mengkonsumsi mikroplastik dengan rata-rata jumlah mikroplastik yang teridentifikasi tidak berbeda secara signifikan dengan rata-rata jumlah mikroplastik yang ditemukan di laut
DOI: https://doi.org/10.30598/TRITONvol16issue1page1-7

bebas China. Berdasarkan hasil penelitian, ditemukannya mikroplastik pada kerang darah yang diambil dari perairan Tanjung Tiram Teluk Ambon Dalam. Dengan ditemukannnya mikroplastik pada kerang darah ini serta didukung dengan beberapa referensi lainnya, maka terbukti bahwa mikroplastik telah dikonsumsi oleh biota perairan dan hal ini berbahaya bagi kelangsungan hidup sumberdaya di perairan maupun manusia sebagai konsumen atau pengguna sumberdaya tersebut.

Hingga saat ini, mikroplastik memang belum ditetapkan sebagai senyawa beracun dengan daya racun (toxicity) tertentu (Widianarko\&Hantoro, 2018). Selannjtnya dikatakan bahwa keberadaan mikroplastik dalam seafood tentu melanggar kriteria keamanan pangan karena tidak ada konsumen yang mengharapkan daging kerang yang disantapnya terdapat kandungan kimia dari plastik yang terserap pada daging kerang. Plastik dapat dipandang sebagai bahan campuran yang tidak diinginkan (adulterant). Plastik memiliki kandungan kimia antara lain PTE (Poly ethylene tere phthalate), polypropylene, polyvinyl chloride yang sangat berbahaya bagi manusia. Jika plastik di perairan ditemukan dalam bentuk mikroplastik dan terakumulasi dalan lambung kerang darah, maka tentunya kandungan kimia dalam plastik akan terserap pula dalam tubuh kerang tersebut. Sejumlah penelitian menunjukkan bahwa mikroplastik berperan sebagai pembawa (carrier) senyawa pencemar organik, tetapi secara mandiri daya racun mikroplastik masih belum jelas terungkap. Dalam kajian keamanan pangan mikroplastik dapat dikelompokkan sebagai pencemar pangan baru (novel food contaminant), karena keberadaannya melanggar kemurnian pangan.

Keberadaan mikroplastik di perairan memang berbahaya bagi kelangsungan hidup manusia, walaupun penelitian ini masih terus dilakukan untuk mendapatkan infromasi ilmiah terkait dampak mikroplastik terhadap kesehatan manusia. Namun demikian, keberadaan mikroplastik dapat dikurangi melalui banyak cara seperti aksi bersih pantai, sosialisasi, penegasan aturan, serta pengunaan teknologi tepat guna. Salah satu teknologi tepat guna yang 
dapat digunakan yaitu bioplastik dengan memanfaatkan bahan baku lokal seperti sagu (Safitri, $d k k .$, 2016; Kamsiati, $d k k .$, 2017) yang merupakan makanan pokok rakyat Maluku serta rumput laut (Putri, 2019) yang merupakan salah satu produk unggulan di perairan Maluku.

\section{KESIMPULAN DAN SARAN}

Berdasarkan uraian dan pembahasan yang telah dijelaskan, maka dapat disimpulkan bahwa mikroplastik telah berada di perairan dan dikosumsi oleh kerang darah (Anadara granosa). Jenis mikroplastik yang ditemukan dalam bentuk fiber dan fragmen. Keberadaan mikroplastik di perairan perlu mendapat perhatian serius karena kandungan kimia plastik yang ikut terserap oleh daging kerang dan dikonsumsi manusia akan membahayakan biota perairan maupun manusia.

Adapun saran yang dapat direkomendasikan berdasarkan hasil penelitian ini yaitu perlu adanya penelitian lanjutan tentang keberadaan dan jenis mikroplastik pada ikan yang dikonsumsi oleh masyarakat.

\section{DAFTAR PUSTAKA}

Andrady, A. L. 2011. Microplastics in the marine environment. Marine Pollution Bulletin, 62 (2011), 1596-1605. https://doi.org/ 10.1016/j.marpolbul.2011.05.030

Ayuningtyas, W. C., D. Yona, S. H. Julinda, F. Iranawati. 2019. Kelimpahan Mikroplastik Pada Perairan di Banyuurip, Gresik, Jawa Timur. Journal Fisheries and Marine Research 3(1): 41-45.

Boerger, C. M., Lattin, G. L., Moore, S. L., \& Moore, C. J. (2010). Plastic Ingestion by Planktivorous Fishes in THE NORTH PACIFIC Central Gyre. Marine Pollution Bulletin, 60(12), 2275-2278. https://doi.org/10.1016/j.marpolbul.2010.08.0 07.

Browne, M.A., Dissanayake, A., Galloway, T.S., Lowe, D.M., Thompson, R.C., 2008. Ingested Microscopic Plastic Translocates to The Circulatory System of The Mussel, Mytilus edulis (L.). Environmental Science and Technology. 42, 5026e5031.
Darmono, 2001. Lingkungan Hidup dan Pencemaran (Hubungannya dengan Toksikologi Senyawa Logam), Penerbit: Universitas Indonesia Press, Jakarta

Fitri, A. 2017. Studi Awal Mikroplastik Pada Kerang Darah (Anadara granosa) dari Tambak Lorok Semarang. Tesis. Universitas Katolik Soegijapranata.

Garcia, B., M. M. Fang, J. Lin. 2019. Marine Plastic Pollution in Asia: All Hands on Deck!. Chinese Journal of Environmental Law 3(1): 11-46. DOI: https://doi.org/10.1163/ 24686042-12340034.

Griet, V., V.C.Lisbeth., J.Colin R., M.Antonio., G.Kit., F.Gabriella., K.Michiel. D.Jorge.,B.Karen., R.Johan., D. Lisa. (2015). A Critical View on Microplastics Quantification in Aquatic Organisms. Eviromental Research, 143: 46 -55.

Hidalgo, V., L. Gutow, R. C. Thompson, M. Thiel. 2012. Microplastics in The Environment: A Review of The Methods Used for Identification and Quantification. Environmental Science and Technology 46(6):3600-3075.

Kamsiati, E., H. Herawati, E. Y. Purwani. 2017. Potensi Pengembangan Plastik Biodegradable Berbasis Pati Sagu dan Ubi Kayu di Indonesia. Jurnal Litbang Pertanian 36(2): 6776. DOI: 10.21082/jp3.v36n2.2017.p67-76.

Li J., D. Yang, Lan Li, K. Jabeen, H. Shi. Microplastic in Commercial Bivalves form China. 2015. Environmental Pollution 207(2015):190-195.

Lusher, A., Hollman, P., \& Mandoza-Hill, J. J. (2017). Microplastics in fisheries and aquaculture. In FAO Fisheries and Aquaculture Technical Paper. https://doi.org/dmd.105.006999[pii]|r10.1124/ dmd.105.006999.

Manullang, C. Y. 2019. The Abudance of Plastic Marine Debris on Beaches in Ambon Bay. IOP Conference Series: Earth and Environmental Science 253 (2019) 012037. doi:10.1088/1755-1315/253/1/012037.

Plastics, E. 2019. Plastics-The Facts 2019 An Analysis of European Plastics Production, Demand and Waste Data. https://www.plasticseurope.org/application/fil es/1115/7236/4388/FINAL_web_version_Plas tics_the_facts2019_14102019.pdf.

Putri, G. R. Karakteristik Bioplastik dari Rumput Laut (Euchema cottonii) dan Pati Singkong Dengan Penambahan Pati Biji Alpukat. 2019. Risenologi (Jurnal Sains, Teknologi, Sosial, 
Pendidikan, dan Bahasa) 4(2): 59-64. p-ISSN : 2502-5643.

Safitri, I., M. Riza, Syaubari. 2016. Uji Mekanik Plastik Biodegradable dari Pati Sagu dan Grafting Poly (Nipam)-Kitosan dengan Penambahan Minyak Kayu Manis (Cinnamomum burmannii) sebagai Antioksidan. Jurnal Litbang Industri 6(2): 107-116. E-ISSn: 2502-5007.

Steibl, S \& Laforsch, C. 2019. Disentangling the Environmental Impact of Different Human Disturbances: A Case Study on Islands. Sci Rep 9, 13712 (2019). https://doi.org/10.1038 /s41598-019-49555-6.

Rochman, C.M., Kurobe T, Flores I, Teh S.J. (2015). Early Warning Signs of Endocrine Disruption in Adult Fish From The Ingestion of Polyethylene With and Without Sorbed Chemical Pollutants From The Marine Environment. Science of The Total Environment 493 656-661. http://dx.doi.org/10.1016/j.scitotenv.2014.06. 051.

Teuten E. L, Saquing J. M., Knappe D. R. U., Barlaz M. A., Jonsson S., Bjorn A., Rowland S. J,
Jurnal TRITON Volume 16, Nomor 1, April 2020, hal. 1 - 7 P-ISSN 1693-6493 E-ISSN 2656-2758

DOI: https://doi.org/10.30598/TRITONvol16issue1page1-7

Thompson R. C., Galloway T. S., and Yamashita R. 2009. Transport and Release of Chemicals from Plastics to The Environment and to Wildlife. Philosophical Transactions of the Royal Society B. 364: 2027-2045. doi:10.1098/rstb.2008.0284.

Tuhumury, N., \& Kaliky, I. 2019. Identifikasi Sampah Pesisir di Desa Rumah Tiga Kota Ambon. TRITON: Jurnal Manajemen Sumberdaya Perairan, 15(1), 30-39. https://doi.org/10.30598/TRITONvol15issue1 page30-39.

Widianarko, B \& I. Hantoro. 2018. Mikroplastik dalam Seafood dari Pantai Utara Jawa. Penerbit Universitas Katolik Soegijapranata. ISBN 978-602-6865-74-8.

Wright, S. L., Thompson, R. C., \& Galloway, T. S. (2013). The Physical Impacts of Microplastics on Marine Organisms: A Review. Environmental Pollution, 178, 483- 492. https://doi.org/10.1016/j.envpol.2013.02.031

Zhang W, Zhang S, Wang J, Wang Y, Mu J, Wang P, Lin X, Ma D. 2017. Microplastic Pollution in The Surface Waters of the Bohai Sea, China. Environ Pollut 231: 541-548. 